University of Wollongong

Research Online

2019

Involvement of people with dementia in raising awareness and changing attitudes in a dementia friendly community pilot project

Lyn Phillipson

University of Wollongong, Iphillip@uow.edu.au

Danika Hall

University of Wollongong, danika@uow.edu.au

Elizabeth Cridland

University of Wollongong, Icridlan@uow.edu.au

Richard Fleming

University of Wollongong, rfleming@uow.edu.au

Christopher R. Brennan-Horley

University of Wollongong, chrisbh@uow.edu.au

See next page for additional authors

Follow this and additional works at: https://ro.uow.edu.au/ahsri

Research Online is the open access institutional repository for the University of Wollongong. For further information contact the UOW Library: research-pubs@uow.edu.au 


\title{
Involvement of people with dementia in raising awareness and changing attitudes in a dementia friendly community pilot project
}

\author{
Abstract \\ Low levels of public understanding can contribute to the fear, stigma and social exclusion associated with \\ living with dementia. Dementia friendly communities aim to address this by empowering people with \\ dementia and increasing their social inclusion. As a part of a Community Based Participatory Action \\ Research (CBPAR) process, a multicomponent dementia friendly community intervention supported: \\ research; the establishment of a Dementia Advisory Group and Alliance; an awareness campaign and \\ education in community organisations. Educational events were co-designed and co-facilitated by people \\ with dementia and their care partners. To assess project reach and changes in attitudes of community \\ members, two cross sectional surveys were conducted with adults (aged over 18 years) using validated \\ scales. Independent samples t-tests compared responses to the surveys prior to the commencement of \\ the project (2014) and two years later (2016). In 2016, respondents showed increased agreement with the \\ statements: 'People with dementia participate in a wide variety of activities and interests,' and, 'It is easy \\ to find out about dementia friendly services or organisations in Kiama'. Respondents who attended an \\ educational event reported less negative views about how they themselves would feel if they were \\ diagnosed with dementia compared with respondents who did not attend an event. CBPAR appears \\ useful to support the involvement of people with dementia and the engagement of the community to \\ improve awareness of dementia services. The direct involvement of people living with dementia as \\ spokespeople and educators was an effective way to improve positive attitudes and reduce the negative \\ stereotypes associated with living with dementia. Further research is needed to compare different \\ approaches to the creation of dementia friendly communities in different locations, and to establish the \\ extent to which local interventions are useful to complement efforts to raise awareness of dementia at a \\ national level

\section{Publication Details} \\ L. Phillipson, D. Hall, E. Cridland, R. Fleming, C. Brennan-Horley, N. Guggisberg, D. Frost \& H. Hasan, \\ "Involvement of people with dementia in raising awareness and changing attitudes in a dementia friendly \\ community pilot project", Dementia 18 7-8 (2019) 2679-2694.
}

\section{Authors}

Lyn Phillipson, Danika Hall, Elizabeth Cridland, Richard Fleming, Christopher R. Brennan-Horley, Nick Guggisberg, Dennis Frost, and Helen M. Hasan 


\title{
L.Phillipson, L, Hall, D, Cridland, E, Fleming, R, Brennan-Horley, C, Guggisberg, N, Frost, D, and Hasan, H (Early view). Involvement of people with dementia in raising awareness and changing attitudes in a dementia friendly community pilot project, Dementia: the international journal of social research and practice. https://doi.org/10.1177/147130121875445
}

Corresponding Author:

Dr Lyn Phillipson, Australian Health Services Research Institute IC Enterprise 234, Innovation Campus, University of Wollongong, Northfields Ave, Wollongong NSW 2522, Australia lphillip@uow.edu.au +61242214773

\begin{abstract}
Low levels of public understanding can contribute to the fear, stigma and social exclusion associated with living with dementia. Dementia friendly communities aim to address this by empowering people with dementia and increasing their social inclusion. As a part of a Community Based Participatory Action Research (CBPAR) process, a multicomponent dementia friendly community intervention supported: research; the establishment of a Dementia Advisory Group and Alliance; an awareness campaign and education in community organisations. Educational events were co-designed and co-facilitated by people with dementia and their care partners. To assess project reach and changes in attitudes of community members, two cross sectional surveys were conducted with adults (aged over 18 years) using validated scales. Independent samples t-tests compared responses to the surveys prior to the commencement of the project (2014) and two years later (2016).

In 2016, respondents showed increased agreement with the statements: 'People with dementia participate in a wide variety of activities and interests,' and, 'It is easy to find out about dementia friendly services or organisations in Kiama'. Respondents who attended an educational event reported less negative views about how they themselves would feel if they were diagnosed with dementia compared with respondents who did not attend an event.

CBPAR appears useful to support the involvement of people with dementia and the engagement of the community to improve awareness of dementia services. The direct involvement of people living with dementia as spokespeople and educators was an effective way to improve positive attitudes and reduce the negative stereotypes associated with living with dementia. Further research is needed to compare different approaches to the creation of dementia friendly communities in different locations, and to establish the extent to which local interventions are useful to complement efforts to raise awareness of dementia at a national level.
\end{abstract}

\section{Background}

Alongside the demographic aging of the population, we are witnessing a corresponding increase in the number of people living with dementia (Alzheimer's Disease International (ADI), 2016, p.10). International estimates are 46 million, with 
this number expected to rise to 138 million by 2050 (ADI, 2016). Despite this, public awareness of dementia remains low, with an international, systematic review finding only fair to moderate knowledge and understanding, and a common misconception that dementia is a normal part of ageing (Cahill, 2015). A World Health Organisation (WHO) survey found that respondents from 25 of 30 surveyed countries felt stigma associated with dementia negatively affected people living with dementia and their carers (WHO \& ADI, 2012). Stigma can adversely affect the physical and mental health of a person living with dementia and exacerbate social isolation and delays in help-seeking and diagnosis (Vernooij-Dassen et al., 2005; WHO \& ADI, 2012). Improving public understanding is a key strategy to improve advocacy and helpseeking and reduce the fear and stigma associated with dementia (Vernooij-Dassen et al., 2005; WHO \& ADI, 2012).

In Australia, there are more than 350,000 people living with dementia (Australian Institute of Health \& Welfare (AIHW), 2012). Without a medical breakthrough, this number is expected to increase to 900,000 by 2050 . Dementia is the single greatest cause of disability in Australians aged over 65 years, and the third leading cause of disability burden overall (AIHW, 2012). Dementia is estimated to become the third greatest source of health and residential aged care spending within two decades (Access Economics, 2009). Yet, a recent national survey of 1003 adults found dementia was only ranked as the sixth most important health issue, after heart disease, stress, obesity, diabetes and prostate cancer (Smith, Ali, \& Quach, 2014). While some Australians do not perceive dementia as a health priority, it is a condition associated with fear and negative stereotypes. A 2010 survey of 2500 Australian adults found $63 \%$ were afraid of getting dementia, second only to their fear of cancer $(66 \%)$ (Pfizer, 2011). The survey found that $22 \%$ of Australians would feel uncomfortable spending time with someone who had dementia. A further $16 \%$ knew someone who might have dementia who had not sought diagnosis or treatment (Pfizer, 2011). The lack of awareness and understanding, and the fear associated with dementia evidences the need for public education and other stigma-reduction strategies. Such programs could prevent the social isolation of people living with dementia, help them to maintain self-esteem, seek help and improve their quality of life (van der Roest et al., 2007; WHO \& ADI, 2012).

\section{Dementia awareness campaigns and dementia friendly communities}

Dementia awareness raising campaigns can vary in their focus to include increasing knowledge and understanding of dementia, reducing the stigma and discriminatory behaviour towards people living with dementia, recognising early signs and symptoms to aid diagnosis, promoting risk reduction behaviours, and living well with dementia (WHO \& ADI, 2012).

Specific campaigns to reduce the stigma of dementia include a ten-year program in Japan where the government changed a stigmatising word previously used for dementia to a more respectful term (WHO \& ADI, 2012). They also provided training to over 2.4 million dementia supporters to increase their understanding and promote advocacy for people living with dementia (WHO \& ADI, 2012). Another campaign, conducted in the United Kingdom, targeted women aged $40-60$ years and used television, radio, newspaper and internet advertising featuring people living with dementia. The key message of, 'I have dementia, I also have a life,' sought to increase awareness, normalise dementia and challenge the misconception that people with dementia are not able to enjoy life (WHO \& ADI, 2012). 
For campaigns to be most effective the whole of civil society should be mobilised and there are growing calls for campaigns to be embedded in broader projects to support the creation of 'dementia friendly communities' (Department of Health, 2012; WHO \& ADI, 2012). A dementia friendly community is defined as 'a place or culture in which people with dementia and their carers are empowered, supported and included in society, understand their rights and recognise their full potential,' (ADI, 2016, p.10). According to ADI, the objectives of dementia friendly communities are to: reduce stigma and increase understanding of dementia by greater awareness and meaningful engagement for people with dementia; and to empower people with dementia by recognising their rights and capability so they feel respected and are empowered to make decisions about their lives (ADI, 2016).

Several models and principles have been conceptualised as important to support the creation of dementia friendly communities (ADI, 2016; Alzheimer's Australia, 2012; Crampton \& Eley, 2013). At the heart of the many definitions of 'dementia friendly' are people living with dementia themselves. Priorities include preservation of personhood (Topo \& Kotilainen, 2009), personal identity, individuality and autonomy (Hadjri, Faith, \& McManus, 2012), and the need to take into consideration the lived experiences of people with dementia (Davis, Byers, Nay, \& Koch, 2009; Marouse \& Charras, 2012).

Examples of dementia friendly initiatives recently documented in 35 countries throughout the world include: 'Alzheimer's Cafés' in the Netherlands; 'Dementia Friends' programs in Japan and the United Kingdom; and the 'Together for a Dementia friendly Bruges' campaign in Belgium (ADI, 2016). Uji in the prefecture of Kyoto, Japan, was declared a 'dementia friendly city' in March 2015.

Programs to support the creation of dementia friendly communities have also recently been initiated within Australia including the Dementia Friendly Kiama project. Dementia Friendly Kiama commenced in June 2014 in the local government area of Kiama, New South Wales, Australia. The purpose of the current study was to pilot a Community Based Participatory Action Research (CBPAR) process to support changes in knowledge, attitudes and beliefs about dementia of people living in the Kiama area. A specific aim was to understand the extent to which education and awareness raising activities, as well as contact with people living with dementia, would increase community understanding of dementia and reduce stigma.

\section{Methods}

Kiama is a local government municipality with a population of over 21,000 people (Australian Bureau of Statistics, 2014). The built form can be described as dispersed, consisting of a small downtown area surrounded by low-density suburbs of free standing family homes. Kiama is an example of what is known in Australia as a 'seachange' town. It is popular with retirees as a place to live out their senior years due to its attractive coastal location, village atmosphere and relative access to cities (Wollongong and Sydney) via a railway corridor. The larger Kiama State Electorate has a population of 69,000 people (Australian Bureau of Statistics, 2011). Due to the ageing demographic profile of the region, the number of people living with dementia in the State Electorate is projected to increase from the current 1200 to almost 4000 by 2050 (Australian Bureau of Statistics, 2012).

The Dementia Friendly Kiama project utilised CBPAR (Israel, Schulz, Parker, \& Becker, 1998) and commenced as a partnership between a university, a peak advocacy body and the municipal council. The university undertook formative research with 
people living with dementia in the Kiama area and their carers, as well as members of the Kiama community (Phillipson, Hall, \& Cridland, 2015). In the early stages of the project, a Dementia Advisory Group (consisting of people living with dementia and their carers) and Dementia Alliance (including members of the Advisory Group, representatives from partner and other relevant organisations, and interested individuals) formed. These groups reviewed the formative research and developed an action plan. Aims of the action plan included increasing community awareness about dementia and local services, promoting understanding of the lived experience of dementia and reducing the stigma of dementia.

Awareness raising and educational activities were co-designed and co-facilitated by members of the Dementia Advisory Group. This was based on their desire for local people to understand their lives and share their awareness - which has also been found in other research (von Kutzlebena, Schmida, Haleka, Hollea, \& Bartholomeyczika, 2012). The decision to support the active involvement of local people with dementia in media and educational events was also based on a previous study of dementia stigma in Australia which found that having contact with a person with dementia was associated with lower levels of personal avoidance of the condition (Phillipson, Magee, Jones, \& Skladzien, 2014).

Education and awareness raising activities over an 18-month period included information and education sessions delivered to over 1000 community members. People living with dementia and their carers participated in all activities sharing their experiences in the media and via presentations and panel discussions at educational events. They were also involved in direct consultation with community organisations, businesses and services including the Chamber of Commerce, service clubs and general practitioners. The project attracted over 30 instances of media attention including radio, TV and print at local, Sydney and national level in which local people living with dementia frequently featured. Four websites featured information about the project, including the project website (www.dementiais.com), which promoted local information, resources and services for people with dementia, a local calendar of events and over 35 news blogs specific to the project. A Dementia Friendly Kiama brand was developed and printed material (including flyers, posters, brochures and newsletters) were widely distributed.

\section{Community survey}

As part of the formative research, members of the Kiama community were invited to complete a survey about their knowledge, attitudes towards, and experiences of, people living with dementia. A 34-item questionnaire was compiled based on two scales previously used in an Australian study of dementia attitudes and stigma (Phillipson et al., 2014). The first validated scale, Perceptions Regarding Investigational Screening for Memory in Primary Care (PRISM-PC) - Dementia Screening Subscale (Boustani et al., 2008), measured how the respondent would feel if they themselves were diagnosed with dementia (e.g., "I would not want my family to know", "I would feel humiliated") (Cronbach's $\alpha \geq 0.77$ ) (Boustani et al., 2008). The second validated scale, Fraboni Scale of Ageism (Fraboni, Saltstone, \& Hughes, 1990), measured stigma and attitudes towards ageing, but were modified to assess attitudes towards people with dementia (Phillipson et al., 2014), rather than elderly people more generally. This was achieved by changing the words 'older people' to 'people with dementia' (Cronbach's $\alpha=0.8$ ) (Phillipson et al., 2014). All items were assessed on a 5-point Likert scale ('strongly agree' to 'strongly disagree'). 
The initial survey was conducted from October to December 2014 and results have been reported elsewhere (Phillipson et al., 2015). A second survey was conducted from March to June 2016 which repeated the attitudinal measures and assessed awareness and involvement in the Dementia Friendly Kiama project. Both surveys were promoted via email, Facebook and links on relevant websites. Further participants were recruited from sign-up sheets or paper surveys handed out at community events.

Paper and online responses were collated, stored, and analysed using SPSS 21 (Allen, 2014). Descriptive statistics were calculated for the combined sample. Independent samples $t$-tests and Pearson's chi-square test of contingencies were conducted to compare the demographics of respondents from the 2014 and 2016 surveys.

Independent samples $t$-tests were performed comparing responses to the attitudinal questions from both surveys (2014 and 2016). Qualitative responses were thematically coded. High level results were reported where relevant to inform interpretation of the quantitative data. Further, within the 2016 results, independent samples $t$-tests were performed comparing responses to the attitudinal questions with a subsample of those who attended Dementia Friendly Kiama events with those who did not.

Results

Respondent characteristics

One hundred and seventy-four community members completed the 2016 survey, compared with 131 in the 2014 survey. In 2014 and 2016, most respondents were female ( $80 \%$ vs $83 \%$ ) and born in Australia (76\% vs 80\%). The mean age of respondents in 2014 and 2016 was 52.34 years and 55.93 years respectively, and in both surveys most respondents were in a relationship (63\% vs $70 \%)$. Similar proportions in $2014(48 \%)$ and $2016(52 \%)$ had completed a University qualification. In both 2014 and 2016 the most frequently reported income group was higher than \$AUD70,000. Only 1\% of participants in the 2014 and 2016 reported having Alzheimer's disease or dementia. A large proportion of respondents knew someone with the condition in 2014 (76\%) and in 2016 (78\%). In 2014, 25\% of respondents and in 2016, 29\% of respondents reported being a current or previous carer for someone with dementia, most commonly a family member. In $2014,30 \%$ of the sample were retired and $62 \%$ working. Whereas in 2016, almost half were retired $(46 \%)$ or working (46\%). For detailed results, see Table 1.

Statistical analysis revealed no significant differences between the 2014 and 2016 samples with regards to: age; gender; country of birth; language spoken at home; marital status; education level; yearly income; or experience with people with dementia. However, significant differences between the samples were found regarding employment status $\left[\chi^{2}(2, \mathrm{~N}=305)=11.107, p=.025\right]$, with a significantly larger proportion of individuals identifying as being retired in the 2016 sample compared to 2014 (also shown in Table 1).

\section{[INSERT TABLE 1 HERE]}

Awareness of and involvement in the Dementia Friendly Kiama project

To assess awareness of the Dementia Friendly Kiama project, 2016 survey respondents were asked if they had received project news or information over the past 
12 to 18 months. Of the 154 respondents completing this question, 68 (44.2\%)

indicated they had received news or information, with the most common format being 'Media Report' $(n=41)$, followed by the 'Dementia Friendly Kiama newsletter' $(n=$ $27)$ and the 'Kiama Council website' $(n=26)$.

Respondents were also asked about their attendance at an event or information session regarding the project over the past 12 to 18 months. Of the 155 people completing this question, 41 (26.4\%) reported attending an event or information session, with 29 indicating attendance at a specific 'Dementia Friendly Kiama' event or information session', and 13 attending the 'Dementia Friends Training' (Alzheimer's Australia NSW, 2016). A further 10 people were involved in the Dementia Alliance and nine in the Dementia Advisory Group.

Community attitudes about people with dementia

In both 2014 and 2016 surveys, respondents indicated generally positive attitudes and perceptions about people with dementia. In the 2016 survey specifically, respondents perceived people with dementia to be valued members of the community; with the majority agreeing that people with dementia participate in a wide variety of activities and interests (54\%); are a good source of knowledge (44\%); and pass on valued traditions $(46 \%)$. Most respondents $(65 \%)$ agreed or strongly agreed that they have a good understanding about dementia and how it affects people. Also, whilst about half the sample (45\%) considered it easy to find out about dementia friendly services or organisations in the Kiama region, a similar proportion were undecided (39\%) or disagreed (12\%). Furthermore, most respondents disagreed with items such as 'people with dementia don't really need to use community facilities' (45\% disagree, 49\% strongly disagree) and 'It is best that people with dementia live where they won't bother anyone' (42\% disagree, $51 \%$ strongly disagree). See Table 2 for mean scores. Various items indicated that most respondents generally felt comfortable being with or talking to someone with dementia. For example, most respondents disagreed or strongly disagreed with items pertaining to trying to avoid eye contact, spending time, or having a conversation with someone with dementia. However, responses indicated some challenges when interacting with people with dementia. For example, whilst a large proportion of respondents disagreed (39\%) to the statement 'complex and interesting conversation could not be expected from most people with dementia', a large proportion of the sample agreed (42\%). Qualitative responses also noted ignorance or a lack of public understanding as a negative aspect of the neighbourhood for people with dementia in both the 2014 and 2016 surveys.

Independent samples $t$-tests were used to compare responses from the 2014 and 2016 samples with regards to attitudes about people with dementia. In the 2016 sample there was significant higher agreement with two attitudinal statements, 'People with dementia participate in a wide variety of activities and interests' $[t(296)=2.53, p=$ .012] and agreement that, 'It is easy to find out about dementia friendly services or organisations in the Kiama area' $[t(295)=2.91, p=.004]$ as shown in Table 2. In both the 2014 and 2016 surveys, qualitative responses confirmed the community's belief that dementia and aged care services and facilities were a positive aspect in the neighbourhood in Kiama for people with dementia. However, in the 2016 survey, qualitative responses revealed a new awareness of the need for more volunteers to spend time with people with dementia. 


\section{[INSERT TABLE 2 HERE]}

Given the higher proportion of retirees in the 2016 sample, further analyses were conducted examining whether there was a significant difference in retired individuals' level of agreement in the above statements (i.e., 'People with dementia participate in a wide variety of activities and interests' and 'It is easy to find out about dementia friendly services or organisations in the Kiama area'). No statistical differences were found, indicating retirees are no more likely to hold positive attitudes regarding these statements than the rest of the 2016 sample.

Responses from the 2016 survey to the attitudinal statements about people living with dementia were also compared for those who had attended an event or information session with those who had not attended. Respondents who had attended events were more likely to disagree that 'people with dementia don't really need to use our community facilities' $[t(153)=2.31, p=.02]$ and 'people with dementia receive priority in care' $[t(153)=1.99, p=.048]$. Respondents who had attended events were also more likely to agree with the statement 'It is easy to find out about dementia friendly services or organisations in the Kiama area' $[t(152)=3.41, p=.001]$.

Community attitudes to a hypothetical scenario that they had dementia

As a means of investigating the anticipated stigma associated with a hypothetical personal diagnosis of dementia, the 2016 community survey evaluated respondent agreement with a series of statements if they themselves had been diagnosed with dementia. In response to this scenario, most respondents indicated that they would feel anxious (80\%) and/or depressed (64\%) if they had dementia; and over a third (37\%) agreed they would no longer be taken seriously if they had dementia, and would be considered stupid and unable to do things (31\%).

Despite a generally negative perception about themselves being diagnosed with dementia, the vast majority (88\%) of respondents agreed that they would like to live in the Kiama area if they had dementia, suggesting most respondents perceive Kiama to be a supportive place to live for people with dementia.

Independent samples $t$-tests were used to compare the 2014 and 2016 samples regarding participants' level of agreement to statements about how they might feel if they were diagnosed with dementia. No statistically significant differences were found, indicating similar attitudes regarding being diagnosed with dementia within the 2014 and 2016 samples as shown in Table 3.

Table 3. 2014 and 2016 participant responses to statements if they were diagnosed with dementia.

\begin{tabular}{|c|c|c|c|}
\hline If I had dementia... & $\begin{array}{l}2014 \text { Mean } \\
\text { Score }( \pm S E)\end{array}$ & $\begin{array}{l}2016 \text { Mean } \\
\text { Score }( \pm S E)\end{array}$ & $p$ \\
\hline I would feel humiliated & $3.98(.08)$ & $4.03(.07)$ & .658 \\
\hline I would no longer be taken seriously & $3.00(.09)$ & $3.19(.08)$ & .094 \\
\hline $\begin{array}{l}\text { I would be considered stupid and unable to } \\
\text { do things }\end{array}$ & $2.94(.09)$ & $3.00(.07)$ & .625 \\
\hline I would be ashamed or embarrassed & $3.18(.09)$ & $3.21(.08)$ & .842 \\
\hline
\end{tabular}


I would be depressed

I would be anxious

I would give up on life

My doctor would not provide the best care for my other medical problems

My doctor and other health professionals would not listen to me

I would not want my health insurance company to find out

I would not want my employer to find out

I would like to live in the Kiama area

I would not want my family to know
$3.03(.09)$

$3.22(.08)$

$2.25(.07)$

$2.40(.06)$

.116

$2.06(.06)$

$2.13(.05)$

.407

$3.50(.08)$

$3.42(.07)$

.467

$3.80(.07)$

$3.82(.07)$

.859

$3.75(.07)$

$3.81(.06)$

$3.38(.08)$

$3.41(.08)$

$2.96(.09)$

$3.12(.08)$

$1.79(.08)$

\section{Attitudes for people who attended a Dementia Friendly Kiama event}

Respondents to the 2016 survey who reported attending a Dementia Friendly Kiama event or information session were compared with those who had not attended, with regards to the statements about 'how you might feel if you found out you had dementia'. Results showed significant differences in responses to the statements, with people who had attended events more likely to disagree with the statements: 'I would not want my family to know' $[t(152)=2.00, p=.047]$; 'I would feel humiliated' $[t(152)=2.75,, p=.007]$; 'I would be ashamed or embarrassed' $[t(152)=3.06, p=$ $.003]$; and 'I would give up on life' $[t(152)=2.48, p=.014]$, see Table 4.

Table 4. 2016 participant responses who attended educational events vs nonattendees.

\begin{tabular}{llllll}
\hline $\begin{array}{l}\text { The following are statements } \\
\text { about how you might feel if you } \\
\text { found out you had dementia. }\end{array}$ & $\begin{array}{l}\text { Mean Score } \\
\text { Attendees } \\
(\mathrm{n}=41)\end{array}$ & $\begin{array}{l}\text { Mean Score } \\
\text { Non- } \\
\text { Attendees } \\
(\mathrm{n}=113)\end{array}$ & $t$ & $d f$ & $p$ \\
\hline $\begin{array}{l}\text { I would not want my family to } \\
\text { know }\end{array}$ & 4.24 & 3.93 & 2.00 & 152 & $0.047^{*}$ \\
$\begin{array}{l}\text { I would feel humiliated } \\
\begin{array}{l}\text { I would no longer be taken } \\
\text { seriously }\end{array}\end{array}$ & 3.56 & 3.08 & 2.75 & 152 & $0.007^{*}$ \\
\begin{tabular}{l} 
I would be considered stupid \\
\hline
\end{tabular} & 3.41 & 2.97 & 1.00 & 152 & 0.32 \\
\hline
\end{tabular}


and unable to do things

I would be ashamed or embarrassed

I would be depressed

I would be anxious

I would give up on life

\section{Discussion}

The Dementia Friendly Kiama pilot used a CBPAR model to support the establishment of a Dementia Alliance and Dementia Advisory Group. These groups worked together with academics from the local university to conduct research which informed the development and implementation of an action plan. The aims of the plan were to increase community awareness and understanding of dementia and reduce stigma in Kiama and surrounding areas. Awareness raising activities used multiple channels including media, face-to-face and website interventions to reach the community with their message. Importantly, people living with dementia and their carers facilitated and designed educational activities; shared experiences via presentations and panel discussions; and consulted with community organisations, businesses and services in the provision of education.

Findings showed significant reach into the community over an 18 -month period and included information and education sessions delivered to over 1000 community members. Results from the 2016 survey suggest the use of multiple communication channels was successful in increasing availability of information about dementia for Kiama residents with a significant increase in agreement to the statement, 'It is easy to find out about dementia friendly services or organisations in the Kiama area' (compared with the 2014 survey results). This was an important achievement given the need for more information about dementia and local services for people with dementia, highlighted as part of the formative research. 'The availability of local sources providing information about health concerns and service referrals' is an indicator recommended by the WHO to measure age-friendliness, and as such, potentially 'dementia friendliness' of cities (WHO, 2015).

Acceptance of dementia from a civil society perspective can take several stages (WHO \& ADI, 2012). Once information is made available and initial awareness is established, greater awareness can be generated via the support of the media, as was the case in the Kiama area. The establishment of local groups, such as the Dementia Alliance and Dementia Advisory Group, and convening of meetings and educational events, supported improved knowledge and, in turn, positive attitudes.

Another specific aim of Dementia Friendly Kiama was to understand the extent to which education and awareness raising activities, as well as contact with people living with dementia, could assist with increasing understanding of dementia and reducing stigma. Positive social attitudes toward older people is an indicator of the inclusiveness of the social environment in measuring the age-friendliness of cities (WHO, 2015). With respect to increasing dementia-friendliness, the 2016 community survey results showed a significant increase in agreement to the statement 'People 
with dementia participate in a wide variety of activities and interests', compared with the 2014 survey. This suggests improved understanding in the Kiama community that people living with dementia can continue to remain active and engaged in meaningful activities despite their diagnosis.

With regards to the specific impact of educational events, respondents to the 2016 survey who attended an educational event were significantly less likely to agree with negative statements (for example 'people with dementia don't really need to use our community facilities'), indicating improved awareness of the need for inclusion of people with dementia in the community. Further, respondents who had attended a project event reported significantly more positive views about how they themselves would feel if they found out they had dementia (compared with respondents who had not attended events or information sessions).

The involvement of people living with dementia as spokespeople and educators at information sessions and 'Dementia Friends' training appears to have been important in improving positive attitudes and reducing stigma. The opportunity for people with dementia to have contact with community members, service providers, and local councillors at Dementia Alliance meetings and as advocates and spokespeople for the project may have helped to reduce stigma. The Dementia Alliance International (DAI) considers this approach, and the Dementia Friendly Kiama project, to be the goldstandard in developing dementia friendly communities (DAI, 2016). The approach is consistent with effective stigma reduction interventions that emphasise the importance of opportunities for contact with a stigmatised group in both mental health (Griffiths, 2014) and to reduce ageism (Christian, 2014).

Supporting contact with people with dementia is evident in other dementia friendly initiatives, for example intergenerational activities those aimed at increasing the understanding of dementia among young people (ADI, 2016). However, direct contact of community members with people with dementia has not been a consistent feature of most awareness raising programs internationally. Some largescale campaigns have been critiqued for their lack of involvement of people living with dementia (DAI, 2016). Evidence from this project suggests that the direct involvement of people living with dementia was an effective way to promote positive attitudes and reduce dementia-related stigma.

\section{Limitations}

Attempts were made to achieve representative demographic quotas for the community surveys via social media recruitment of survey participants. However, convenience sampling was also used. As such, whilst the demographic samples of respondents from the 2014 and 2016 surveys do not differ considerably from one another, they may not be considered representative of the general Kiama community. Most notably, there was an overrepresentation of females in the survey.

Second, regarding the findings that people who attended education developed more positive attitudes when anticipating a diagnosis of dementia, it is also possible that people with more positive attitudes may have self-selected to attend education. This, however, is not supported by other evaluation data collected during follow-up interviews with people with dementia and their carers in 2016 which indicated many had experienced a positive shift in community attitudes towards dementia across the intervention (Phillipson, Hall \& Cridland, 2016).

Thirdly, as there was no control community, changes in general community awareness and attitudes in Kiama could have occurred as a result of awareness raising 
efforts at the state or national level. This conclusion is not supported by results from a recent national dementia attitudes survey conducted by Alzheimer's Australia which indicates the persistence of high levels of stigma and negative attitudes towards people living with dementia (Alzheimer's Australia, 2017). It would also not account for the specific changes in community awareness concerning 'information and services about dementia in Kiama' which has not been the focus of any other campaigns. That said, future research would benefit from the allocation of the considerable resources required to assess outcomes over time in a control community (which was beyond the scope of the current pilot study).

Finally, given the growing interest in supporting the creation of dementia friendly communities, further research is urgently needed to compare different approaches in different types of locations, and to establish the extent to which local, tailored interventions are useful to complement efforts to raise awareness of dementia at a national level.

\section{Conclusion}

The Dementia Friendly Kiama project highlights the benefits of awareness raising and educational activities conducted as part of a CBPAR intervention. Use of multiple communication channels was successful in increasing the availability of information about dementia services and supports in the local community. Attendance at education events was most significantly associated with more positive attitudes and the reduction of stigma associated with living with dementia. The direct involvement of people living with dementia as co-designers and spokespeople in media and at events played a critical role. This highlights the benefits of dementia friendly initiatives supporting not only education about dementia but opportunities for contact with, and leadership by people living with dementia.

\section{Acknowledgements}

Members of the Southern Dementia Advisory Group and the Dementia Alliance who supported the conduct of the research, and the development and implementation of the Local Action Plan. Kate Swaffer, Kylie Watkins and Ellen Skladzien (formerly of Alzheimer's Australia) who were involved in the start-up phase of the project. Danielle White from Alzheimer's Australia NSW who was responsible for the cofacilitation of some of the education sessions.

\section{Funding statement}

The formative research and evaluation of the Dementia Friendly Kiama project was funded by two grants (an initial seed grant and a subsequent project grant) by the University of Wollongong 'Global Challenges' initiative. Alzheimer's Australia initially funded a part time project officer to support the first 12 months of the project. They also employed a person with dementia to mentor and support the establishment of the Dementia Advisory Group. The activities associated with the project were funded by a Livable Communities Grant (awarded to Kiama Council). Alzheimer's Australia, Kiama Council and the University of Wollongong also made in-kind contributions to support project meetings, educational events and staff time. The funding bodies had no role in the design of the study and collection, analysis, and interpretation of data, nor in the writing of the manuscript. 


\section{Declaration of conflicting interests}

The authors declare that they have no competing interests.

\section{Ethics approval}

University of Wollongong Human Research Ethics Committee Approval HE14/065 'Informing and evaluating the impact of the Dementia Friendly Communities and Organisations Strategy. A pilot study in the Kiama Local Government Area'

\section{Commonly used abbreviations}
ADI Alzheimer's Disease International
DAI Dementia Alliance International
WHO World Health Organisation

\section{References}

Access Economics. (2009). Keeping dementia front of mind: Incidence and prevalence 2009-2050. Retrieved from:

https://www.fightdementia.org.au/publications/access-economics-reports

Allen, P., Bennett, K., \& Heritage, B. (2014). SPSS statistics version 22: A practical guide. South Melbourne: Cengage Learning Australia.

Alzheimer's Disease International. (2016). Dementia friendly communities: Key principles. Retrieved from: https://www.alz.co.uk/adi/pdf/dfc-principles.pdf

Alzheimer's Australia. (2012). Dementia friendly societies: The way forward. A report for Alzheimer's Australia paper 31. Retrieved from: https://www.fightdementia.org.au/sites/default/files/20130604_NAT_PUB_Paper 31DementiaFriendlySocieties.pdf

Alzheimer's Australia NSW. (2016). Dementia friends initiative. Retrieved from https://www.dementiafriendly.org.au/sites/default/files/DFK-Friends.pdf

Alzheimer's Australia. (2017). Dementia and the impact of stigma. Retrieved from: https://www.fightdementia.org.au/dementia-and-stigma

Australian Bureau of Statistics. (2011). 2011 Census QuickStats: Kiama state electoral divisions. Retrieved from: 
http://www.censusdata.abs.gov.au/census_services/getproduct/census/2011/quick stat/SED10038?opendocument\&navpos=220

Australian Bureau of Statistics. (2012). Australian social trends: People identified as having dementia or Alzheimer's disease. Retrieved from: http://abs.gov.au/AUSSTATS/abs@.nsf/Lookup/4102.0Main+Features50Dec+20 12

Australian Bureau of Statistics. (2014). Kiama region data summary. Retrieved from: http://stat.abs.gov.au/itt/r.jsp?RegionSummary\&region=14400\&dataset=ABS_R EGIONAL_LGA\&geoconcept=REGION\&datasetASGS=ABS_REGIONAL_AS GS\&datasetLGA=ABS_REGIONAL_LGA\&regionLGA=REGION\&regionASG $\mathrm{S}=\mathrm{REGION}$

Australian Institute of Health \& Welfare. (2012). Dementia in Australia. Retrieved from: https://www.aihw.gov.au/reports/dementia/dementia-inaustralia/contents/table-of-contents

Boustani, M., Perkins, A. J., Monahan, P., Fox, C., Watson, L., Hopkins, J., . . . Hendrie, H. C. (2008). Measuring primary care patients' attitudes about dementia screening. International Journal of Geriatric Psychiatry, 23(8), 812-820. doi:10.1002/gps.1983

Cahill, S. (2015). A systematic review of the public's knowledge and understanding of Alzheimer's disease and dementia. Alzheimer Disease and Associated Disorders, 29(3), 255-275. doi:10.1097/WAD.0000000000000102

Christian, J., Turner, R, Holt, N, Larkin, M, Howard Cotler, J. (2014). Does intergenerational contact reduce ageism: When and how contact interventions actually work? Journal of Arts and Humanities, 3(1), 1-15.

Crampton, J., \& Eley, R. (2013). Dementia friendly communities: What the project "creating a dementia friendly York" can tell us. Working With Older People, 17(2), 49-57. doi:10.1108/13663661311325463 
Davis, S., Byers, S., Nay, R., \& Koch, S. (2009). Guiding design of dementia friendly environments in residential care settings: Considering the living experiences. Dementia, 8(2), 185-203. doi:10.1177/1471301209103250

Dementia Alliance International. (2016). Dementia enabling. Retrieved from: http://www.dementiaallianceinternational.org/dementia friendly-communities/

Department of Health. (2012). Prime Minister's challenge on dementia: Delivering major improvements in dementia care and research by 2015. Retrieved from: https://www.gov.uk/government/publications/prime-ministers-challenge-ondementia

Fraboni, M., Saltstone, R., \& Hughes, S. (1990). The Fraboni Scale of Ageism (FSA): An attempt at a more precise measure of ageism. Canadian Journal on Aging, 9(1), 56-66. doi:10.1017/S0714980800016093

Griffiths K.M., C.-A. B., Parsons A., \& Reid R. (2014). Effectiveness of programs for reducing the stigma associated with mental disorders. A meta-analysis of randomized controlled trials. World Psychiatry, 13, 161-175.

Hadjri, K., Faith, V., \& McManus, M. (2012). Designing dementia nursing and residential care homes. Journal of Integrated Care, 20(5), 322-340.

Israel, B. A., Schulz, A. J., Parker, E. A., \& Becker, A. B. (1998). Review of community-based research: Assessing partnership approaches to improve public health. Annual Review of Public Health, 19(1), 173-202. doi:10.1146/annurev.publhealth.19.1.173

Marouse, O., \& Charras, K. (2012). From blocks to spaces: An occupational therapy approach of toilet block design for Alzheimer's disease. NPG Neurologie Psychiatrie - Gériatrie, 12(67), 15-23.

Pfizer. (2011). Dementia is everybody's business. Retrieved from: https://www.fightdementia.org.au/files/20110314_Nat_report_Pfizer-HealthReport-2011.pdf 
Phillipson, L., Cridland, L., Hall, D. (2015). Dementia Friendly Kiama progress research report. Centre for Health Initiatives, University of Wollongong

Phillipson, L., Hall, D., \& Cridland, L. (2015). Dementia Friendly Kiama project update. Retrieved from: http://dementiaillawarra.com/wpcontent/uploads/2014/07/Dementia-project-update-flyer.pdf

Phillipson, L., Hall, D. \& Cridland, L. (2016). Dementia Friendly Kiama pilot project evaluation 2016. Retrieved from: http://dementiaillawarra.com/wpcontent/uploads/2016/12/DFK-Evaluation-Flyer-WEB.pdf

Phillipson, L., Magee, C. A., Jones, S. C., \& Skladzien, E. (2014). Correlates of dementia attitudes in a sample of middle-aged Australian adults. Australasian Journal of Ageing, 33(3), 158-163. doi:10.1111/j.1741-6612.2012. 00624.x

Smith, B. J., Ali, S., \& Quach, H. (2014). Public knowledge and beliefs about dementia risk reduction: a national survey of Australians. BMC Public Health, 14(1), 661. doi:10.1186/1471-2458-14-661

Topo, P., \& Kotilainen, H. (2009) Designing enabling environments for people with dementia, their family carers and formal carers. In: Assistive Technology Research Series: Dementia, Design and Technology, (24), 45-59.

van der Roest, H. G., Meiland, F. J. M., Maroccini, R., Comijs, H. C., Jonker, C., \& Dröes, R.-M. (2007). Subjective needs of people with dementia: a review of the literature. International Psychogeriatrics, 19(3), 559-592. doi:10.1017/S1041610206004716

Vernooij-Dassen, M. J., Moniz-Cook, E. D., Woods, R. T., De Lepeleire, J., Leuschner, A., Zanetti, O., . . Iliffe, S. (2005). Factors affecting timely recognition and diagnosis of dementia across Europe: from awareness to stigma. International Journal of Geriatric Psychiatry, 20(4), 377-386. doi:10.1002/gps.1302

von Kutzlebena, M., Schmida, W., Haleka, M., Hollea, B., \& Bartholomeyczika, S. (2012). Community-dwelling persons with dementia: What do they need? What 
do they demand? What do they do? A systematic review on the subjective experiences of persons with dementia. Aging \& Mental Health, 16(3), 378-390. doi:10.1080/13607863.2011.614594

World Health Organisation. (2015). Measuring the age-friendliness of cities: A guide to using core indicators. Retrieved from:

http://www.who.int/kobe_centre/publications/AFC_guide/en/

World Health Organisation and Alzheimer's Disease International. (2012). Dementia: A public health priority. Retrieved from: http://www.who.int/mental_health/publications/dementia_report_2012/en/ 
Table 1. Demographic profile of survey respondents from 2014 and 2016.

\begin{tabular}{|c|c|c|c|c|c|}
\hline \multirow[t]{2}{*}{ Variables } & \multicolumn{2}{|l|}{2014} & \multicolumn{2}{|l|}{2016} & \multirow[b]{2}{*}{$p$} \\
\hline & $N=131$ & $\%$ & $N=174$ & $\%$ & \\
\hline${ }^{1}$ Mean Age (SE) & 52.34 & $(1.53)$ & 55.93 & $(1.31)$ & .076 \\
\hline${ }^{2}$ Gender, Female & 105 & 80 & 144 & 83 & .561 \\
\hline${ }^{2}$ Country of birth, Australia & 99 & 76 & 139 & 80 & .368 \\
\hline${ }^{2}$ Language spoken at home, English & 123 & 94 & 163 & 94 & .939 \\
\hline${ }^{2}$ Employment Status & & & & & $0.014^{*}$ \\
\hline Unemployed/Not working & 11 & 8 & 9 & 5 & \\
\hline Retired & 39 & 30 & 80 & 46 & \\
\hline Working & 81 & 62 & 85 & 49 & \\
\hline${ }^{2}$ Marital Status & & & & & .167 \\
\hline Single/Divorced/Widowed & 49 & 37 & 52 & 30 & \\
\hline Married/Defacto & 82 & 63 & 122 & 70 & \\
\hline${ }^{2}$ Highest Level of Education & & & & & .652 \\
\hline Primary/Secondary & 28 & 22 & 38 & 22 & \\
\hline Trade/Other Certificate & 40 & 30 & 45 & 26 & \\
\hline University & 63 & 48 & 91 & 52 & \\
\hline${ }^{2}$ Yearly Income & & & & & .688 \\
\hline$\$ 25,000-\$ 40,000$ & 36 & 28 & 45 & 27 & \\
\hline$\$ 40,001-\$ 70,000$ & 36 & 19 & 42 & 25 & \\
\hline$\$ 70,001$ or more & 55 & 43 & 81 & 48 & \\
\hline $\begin{array}{l}{ }^{2} \text { Do you have Alzheimer's disease or } \\
\text { another type of dementia? No }\end{array}$ & 129 & 99 & 172 & 99 & .740 \\
\hline $\begin{array}{l}{ }^{2} \text { Do you know anyone who has } \\
\text { Alzheimer's disease or another type of } \\
\text { dementia? Yes }\end{array}$ & 98 & 76 & 136 & 78 & .586 \\
\hline${ }^{2}$ Primary carer for person with dementia & & & & & .549 \\
\hline
\end{tabular}




\begin{tabular}{|l|l|l|l|l|l|}
\hline No & 75 & 75 & 97 & 71 & \\
\hline Yes, a family member & 16 & 16 & 26 & 19 & \\
\hline Yes, other & 9 & 9 & 13 & 10 & \\
\hline
\end{tabular}

$1 t$-test statistical analysis. Data are continuous and presented as means and standard deviation; 2 chi-square statistical analysis; ${ }^{*} p<.05 ; * * p<.01$

Table 2. 2014 and 2016 survey respondent agreement to statements about people with dementia.

\begin{tabular}{|c|c|c|c|}
\hline Statements about people with dementia & $\begin{array}{l}2014 \text { Mean } \\
\text { Score }( \pm S E)\end{array}$ & $\begin{array}{l}2016 \text { Mean } \\
\text { Score }( \pm \text { SE })\end{array}$ & $\mathrm{p}$ \\
\hline $\begin{array}{l}\text { Complex and interesting conversation cannot } \\
\text { be expected from most people with dementia }\end{array}$ & $3.12(.09)$ & $3.22(.08)$ & .388 \\
\hline $\begin{array}{l}\text { People with dementia are respected for their } \\
\text { wisdom }\end{array}$ & $3.23(.08)$ & $3.28(.07)$ & .635 \\
\hline $\begin{array}{l}\text { Most people with dementia would be } \\
\text { considered to have poor personal hygiene }\end{array}$ & $3.51(.07)$ & $3.59(.07)$ & .460 \\
\hline $\begin{array}{l}\text { Most people with dementia can be irritating } \\
\text { because they tell the same stories over and } \\
\text { over again }\end{array}$ & $3.04(.09)$ & $3.21(.08)$ & .169 \\
\hline $\begin{array}{l}\text { People with dementia live mostly } \\
\text { independently }\end{array}$ & $3.73(.07)$ & $3.62(.06)$ & .245 \\
\hline $\begin{array}{l}\text { People with dementia don't really need to use } \\
\text { our community facilities }\end{array}$ & $4.50(.06)$ & $4.40(.05)$ & .223 \\
\hline $\begin{array}{l}\text { It is best that people with dementia live where } \\
\text { they won't bother anyone }\end{array}$ & $4.55(.05)$ & $4.41(.06)$ & .079 \\
\hline $\begin{array}{l}\text { The company of most people with dementia is } \\
\text { quite enjoyable }\end{array}$ & $2.43(.06)$ & $2.36(.06)$ & .428 \\
\hline $\begin{array}{l}\text { I would try and avoid eye contact with } \\
\text { someone if I thought they had dementia }\end{array}$ & $4.34(.07)$ & $4.46(.05)$ & .194 \\
\hline People with dementia pass on valued traditions & $2.64(.08)$ & $2.53(.07)$ & .286 \\
\hline $\begin{array}{l}\text { I don't like when people with dementia try to } \\
\text { make conversation with me }\end{array}$ & $4.37(.05)$ & $4.34(.05)$ & .676 \\
\hline $\begin{array}{l}\text { I personally would not like to spend much } \\
\text { time with a person with dementia }\end{array}$ & $4.16(.07)$ & $3.99(.07)$ & .086 \\
\hline
\end{tabular}




\begin{tabular}{|c|c|c|c|}
\hline $\begin{array}{l}\text { People with dementia participate in a wide } \\
\text { variety of activities and interests }\end{array}$ & $2.81(.08)$ & $2.54(.07)$ & $.012 *$ \\
\hline $\begin{array}{l}\text { People with dementia are a good source of } \\
\text { knowledge }\end{array}$ & $2.64(.07)$ & $2.50(.06)$ & .135 \\
\hline $\begin{array}{l}\text { I would prefer not to go to a social group, if } \\
\text { people with dementia were also invited }\end{array}$ & $4.27(.06)$ & $4.18(.06)$ & .263 \\
\hline People with dementia receive priority in care & $3.45(.08)$ & $3.49(.07)$ & .738 \\
\hline $\begin{array}{l}\text { I wouldn't bother visiting a person with } \\
\text { dementia because they wouldn't remember } \\
\text { that I came }\end{array}$ & $4.40(.06)$ & $4.45(.05)$ & .447 \\
\hline $\begin{array}{l}\text { People with dementia have care and concern } \\
\text { for other people }\end{array}$ & $2.35(.08)$ & $2.29(.06)$ & .530 \\
\hline $\begin{array}{l}\text { There is no point in talking to someone with } \\
\text { dementia because they can't take in what I say }\end{array}$ & $4.26(.06)$ & $4.32(.05)$ & .353 \\
\hline $\begin{array}{l}\text { I have a good understanding about dementia } \\
\text { and how it affects people }\end{array}$ & $2.56(.09)$ & $2.36(.07)$ & .080 \\
\hline $\begin{array}{l}\text { It is easy to find out about dementia friendly } \\
\text { services or organisations in the Kiama area }\end{array}$ & $2.99(.08)$ & $2.69(.07)$ & $004 * *$ \\
\hline
\end{tabular}

${ }^{*} p<0.05 ; * * p<0.01$ (two tailed) 